\title{
TRANSIÇÕES RELATADAS POR MULHER ADULTA - SUBSÍDIOS AO MODELO DE ADAPTAÇÃO HUMANA DE SCHLOSSBERG
}

\author{
Antonia Silva Paredes Moreira* \\ Rosalina Aparecida Partesani Rodrigues**

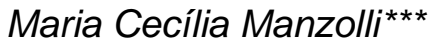

MOREIRA, A. S. P.; RODRIGUES, R. A. P.; MANZOLLI, M.C. Transições relatadas por mulher adulta - subsídios ao modelo de adaptação humana de Schlossberg. Rev.latino-am.enfennagem, Ribeirão Preto, v. 4, n, 1, p. 177-87, janeiro 1996.

Através de um estudo de caso, as transições e crises experienciadas foram expressas por uma mulher, em fase de vida adulta. com 42 anos. O conteúdo da fala é apresentado neste trabalho usando para isto o modelo de adaptação humana proposto por SCHLOSSBERG, com os objetivos de obter-se informações sobre crises e transições, assumir a postura de entrevistador não normativo e aplicar um modelo oriundo da Psicologia na Enfermagem, Utilizou-se a técnica de análise de conteúdo para analisar a entrevista. Verificou-se neste estudo que a pessoa enquanto mulher adulta conseguiu trabalhar suas crises em direção a sua adaptação, utilizando-se de recursos pessoais.

UNITERMOS: mulher adulta, não normatividade. transição

\footnotetext{
* Professor Adjunto do Departamento de Enfermagem de Saúde Pública e Psiquiatria CCS Universidade Federal da Paraíba. Doutoranda do Programa de Pós-Graduação - Nível Doutorado - Área Enfermagem Fundamental da Escola de Enfermagem de Ribeirão Preto da Universidade de São Paulo

** Professor Doutor do Departamento de Enfermagem Geral e Especializada da Escola de Enfermagem de Ribeirão Preto da Universidade de São Paulo

*** Professor Associado do Departamento de Enfermagem Psiquiátrica e Ciências Humanas da Escola de Enfermagem de Ribeirão Preto da Universidade de São Paulo
} 


\section{CONSIDERANDO O MODELO DE SCHLOSSBERG}

O ser humano passa por momentos críticos ao longo de seu desenvolvimento quer na infância, na adolescência, na juventude, na maturidade e na velhice. Em cada estágio a pessoa reage, de acordo com inúmeras variáveis contingenciais peculiares ao seu modo de vida, como um ser em ascensão no trabalho, na vida social, pessoa e transpessoal, numa continuidade do processo vital. Uma descontinuidade neste processo, manifestada por uma paralisação caracteriza-se uma crlse.

$\mathrm{Na}$ visão de SCHLOSSBERG (1982) no tocante à maturidade, ocorre momentos denominados de transições ou crises. Tal fator provoca uma descontinuidade na percepção de vida onde a história fica descontínua, ocorrendo uma fragmentação no processo de viver, pois cada etapa de vida é conseqüência da anterior. Sabe-se que todo ser humano têm experiências de crise psicológica ou transições, pois fazem parte do seu caminhar como um contínuo. Isto não quer dizer que em outros momentos não haja transições, mas as que surgem na maturidade, foco de interesse deste trabalho são dignas de destaque. Além do que, o adulto já tem acrescentado ao seu percurso uma bagagem psicogenética, um "background" histórico e sociocultural.

A posição de SCHLOSSBERG (1982) sobre o desenvolvimento do homem adulto é de concepção não normativa. Para ele, a pessoa vive num mundo dinâmico, de relações interpessoais, dando e recebendo atenção, afeto, trabalho, carinho, isto é, participando socialmente em grupos onde influencia e é influenciado. Além disso, vive num certo lugar do planeta, num dado instante social e histórico, com seus questionamentos intrínsecos a serem resolvidos ou não, em que tudo muda, os valores, normas, opiniões e a própria ciência.

Neste ambiente complexo, o indivíduo enfrenta momentos de mudanças focalizados por SCHLOSSBERG (1982) como transições. Estas podem ter percursos diversos. Ele considera de grande importância o discurso não normativo, assinalando como ponto de referência o curso de vida. Aponta a ocorrência ou não de eventos biopsicossociais capazes de afetarem ou não a vida do homem em vários aspectos realçando a importância do autoconceito na percepção que se tem do mundo e nas relações estabelecidas com este.

Por este ângulo vê-se que se posicionar não normativamente diante do desenvolvimento adulto é assumir uma postura aberta, que é isenta de fatalismo. Como base nestes pontos iniciais pode-se entender que autores não normativos admitem eventos que são marcos de transições evidenciadas por ocasião de eventos, como casamento, nascimento do primeiro filho, ascensão de status profissional, definição do estado civil, morte de pais, filhos, entre outros.

Acentuam, por sua vez, que as pessoas vão experienciando as diversas perdas e acréscimos no decorrer da vida de acordo com o referencial da própria 
existência e as circunstâncias histórico-sociais ocorridas no contexto em que se encontra.

Direcionando o presente estudo pela ótica da não normatividade foi adotada a proposta de SCHLOSSBERG (1982) enquanto um teórico não normativista a respeito do desenvolvimento humano. Isto deu margem a que se pensasse acerca dos vários aspectos que envolvem a sua aproximação à Enfermagem, enquanto esta trabalha com adultos.

Partindo de tal posicionamento, encontrou-se no autor referenciais capazes de subsidiar uma série de opções na tentativa de se entender a pessoa em transição.

Pode-se assim observar no modelo de SCHLOSSBERG (1982) que ele enfatiza as transições as quais podem vir ou não acompanhadas de um evento marcante; que as características das transições contidas na própria pessoa são singulares; que as características ambientais na pré e pós-transição precisam ser consideradas, que a pessoa tem sua capacidade própria de adaptação aos fatos que ocorrem. Estas características podem levar a caminhos que o pesquisador poderá percorrer.

Para visualizar o exposto por SCHLOSSBERG (1982) organizou-se a figura que se segue na página seguinte, tendo-se o cuidado de adaptá-la a realidade em que se vive.

Assim, numa leitura dos aspectos contidos no modelo de SCHLOSSBERG (1982) observa-se os seguintes tópicos: Com relação ao item 1 - a transição na maturidade pode ser vista como resultante de mudanças que ocorrem nas relações sociais levando o indivíduo ao crescimento ou à deteorização. 0 item 2 , observa-se que as características da transição se relacionam à possibilidade da pessoa partir para uma mudança de papel, ser acometida de emoções, novas fontes, com previsibilidade conhecida ou não, que podem apresentar um desenvolvimento, com ritmo e duração próprios, entre outros. No item 3, encontra-se as características ambientais onde a pessoa se encontra neste ambiente, ela se depara com sistemas de apoio fracos ou fortes, com relação social de intensa ou tênue intimidade, suportes institucionais, enfim, de todo o ambiente físico, ecológico e cultural. No item 4, são realçadas as características inerentes ao indivíduo, sendo contemplados tópicos como: sexo, competência psicosocial, idade, raça, nível socioeconômico, valores, vivências anteriores semelhantes entre outras; finalmente, no item 5 aborda a adaptação ao longo do processo em que pode haver reorganização da personalidade, conhecimentos dos próprios recursos, da comunidade, seguida de uma reelaboração de percepções e tomada de decisões.

No conjunto, SCHLOSSBERG (1982) vê a mudança de uma forma abrangente incluindo ganhos e perdas no status e papéis sociais, profissionais, pessoais, em que as emoções permeiam, facilitando, bloqueando ou conjuntamente interferindo na ação da pessoa. Isto, contudo, não é linear, depende da fonte interna do organismo e/ou externa. A imprevisibilidade está presente a todo instante, ao lado de aspectos possivelmente previsíveis. 


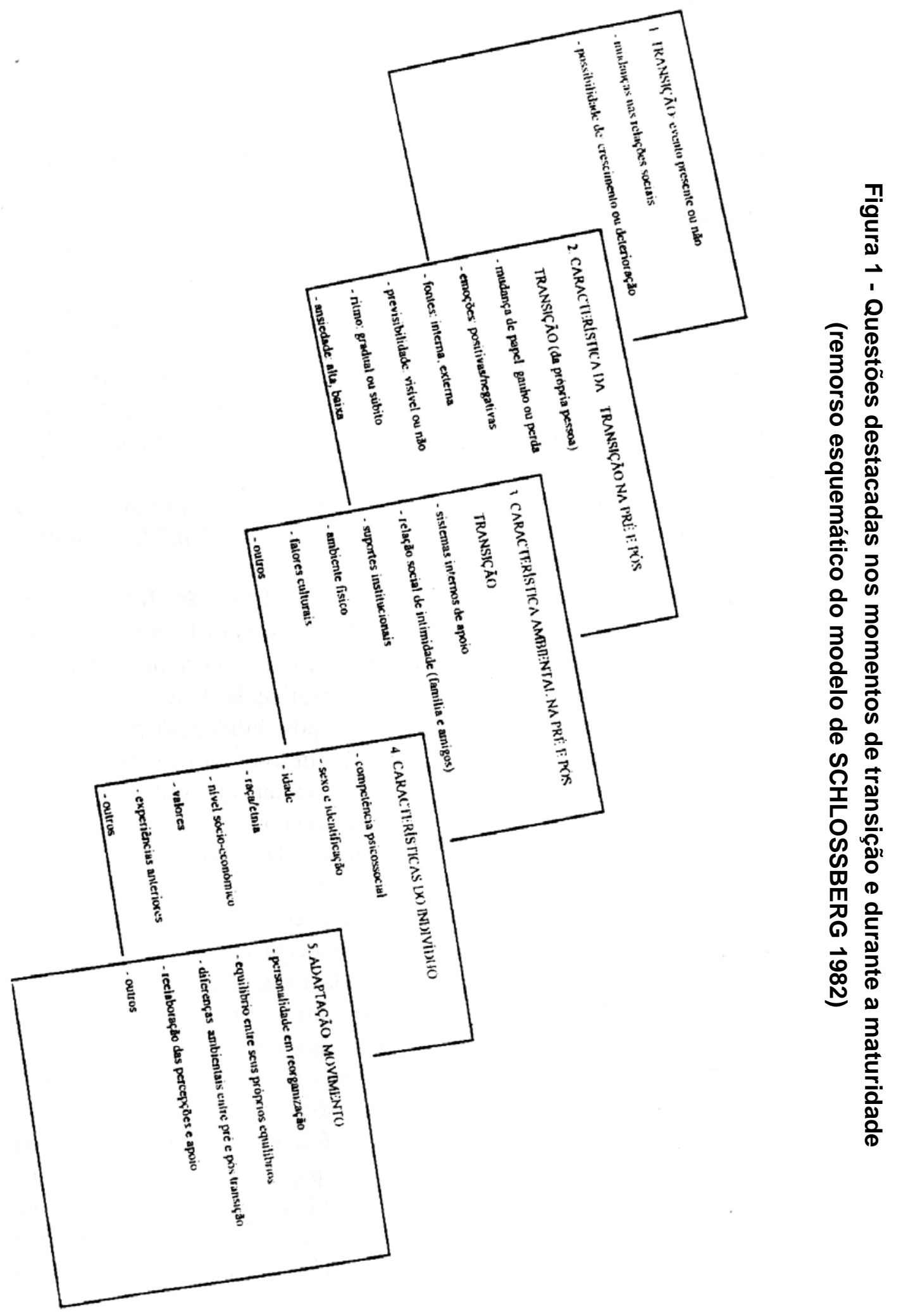


o autor ressalta ainda, o ritmo da transição, que lhe é peculiar tanto no contexto geral como em cada instante. Além disso, se superpõe com o período anterior e posterior do momento de pico, ou seja, na pré e pós-transição, levando em conta o que a sociedade, os grupos sociais como a família, trabalho, igreja, oferecem ou neguem a pessoa, sem perder de vista o potencial genético e a possibilidade de ocorrer desenvolvimento pessoal.

Como se pode ver, o quadro proposto pelo não normativista em apreço é bastante complexo, dinâmico e abrangente.

Ao meio de todos esses eventos variáveis e, em suma, a pessoa chega a um ponto crítico, ela cresce, superando ou apresentando deteriorações.

Partindo dessa compreensão de adulto e pensando a Enfermagem, vê-se que ela pode se relacionar com a pessoa em transição considerando esta relação como uma oportunidade significativa de se fazer presente como profissional não normativo. Isto porque, o modelo de SCHLOSSBERG (1982) oferece oportunidade de se atuar sem preconceitos ou esquemas pré-estabelecidos sobre a pessoa em transição. Enfim, leva o profissional a enxergar o "aqui-agora" sem esquemas previsíveis e numa linha de pensamento contextual.

A partir dessas considerações, este estudo teve como objetivos os de obter informações junto a uma mulher adulta sobre seu viver em transições, segundo o modelo de SCHLOSSBERG (1982), assumir uma postura de entrevistador tendo como guia norteador a sugestão do citado modelo e refletir sobre a aplicabilidade deste, pela Enfermagem.

\section{FOCALIZANDO A METODOLOGIA}

Trata-se de um estudo de caso, com uma mulher adulta com 42 anos de idade, que concordou em participar da pesquisa. É solteira, secretária de uma instituição pública, branca, nível socioeconômico médio e vive com a mãe.

Os passos metodológicos no estudo de caso em pauta foram desenvolvidos a partir da realização de uma entrevista semi estruturada, subsidiada na seguinte questão: "Descreva as transições que você vivenciou em sua vida adulta".

As respostas foram registradas em um diário de campo (tipo bloco), segundo conceito de MINAYO (1994) e os dados coletados foram analisados e interpretados utilizando-se a técnica da análise de conteúdo, citada por BARDIN (1991).

Esta análise consistiu em agrupar os dados em categorias, a partir das unidades de análises contidas na fala da entrevistada, as quais foram subsidiadas nos itens contidos, no modelo teórico de SCHLOSSBERG (1982), conforme descrito. As unidades de análise temática corresponderam às frases emitidas 
espontaneamente pela entrevistada, as quais foram agrupadas semanticamente.

Em seguida, os dados foram transcritos e analisados segundo a referida técnica. Selecionou-se, pois, as unidades de análise, agrupando-as nas categorias pré-estabelecidas conforme modelo do autor em apreço.

As cinco categorias emergentes, com suas respectivas sub categorias, compuseram a figura 1. Estas foram definidas e codificadas da seguinte forma:

Categoria 1: TOE-TRANSIÇÃO COM OCORRÊNCIA E NÃO OCORRÊNCIA DE EVENTOS - compreende todas as unidades de análise cujos "núcleos de sentido" encontram-se inseridos em "mudanças" nas relações sociais com possibilidade de crescimento ou deterioração. Englobam também todas as unidades de análise que corresponderam às "não mudanças" nas relações sociais. Esta categoria integra as seguintes sub categorias:

TOE 1 - mudanças nas relações sociais; TOE 2 - possibilidade de crescimento ou deterioração no desenvolvimento pessoal; TONE 1 - transição com não ocorrência de evento; TONE 2 - transição com ocorrência e com possibilidade de não deterioração.

Categoria 2: CAS-CATEGORIAS DE TRANSIÇÃO NA PRÉ E PÓS TRANSIÇÃO (DA PRÓPRIA PESSOA) - correspondem todas as unidades de análise as quais contemplam os seguintes aspectos pessoais: mudança de papel (ganho ou perda), emoções (positivas ou negativas), fonte (interna ou externa), previsibilidade (prevista ou não prevista), início (gradual ou súbito), duração (permanente, temporária ou incerta) e grau de ansiedade. Nesta categoria encontram-se as seguintes subcategorias:

CAS 1 - mudança de papel; CAS 2 - emoções e/ou sentimento; CAS 3 - grau de ansiedade.

Categoria 3: CAPA-CARACTERÍSTICAS PRÉ E PÓS TRANSIÇÃO englobam unidades de análise que contemplam os seguintes itens: os sistemas internos de apoio (relações de intimidade, unidade de família, rede de amigos), suportes institucionais, ambiente físico e os fatores culturais. Apresenta as seguintes sub categorias:

CAPA/t1 - sistemas internos de apoio com relação a intimidade; CAPA/t2 sistemas institucionais, ambiente físico e fatores culturais.

Categoria 4: CI-CARACTERÍSTICAS DO INDIVÍDUO - arrola as seguintes unidades de análise, as quais apontam para os seguintes aspectos: competência psicossocial (sexo e identificação do papel sexual, idade, saúde, raça e etnia), nível sócio-econômico, orientação de valor e experiência com uma transição parecida. Esta, compreende as seguintes sub categorias:

CI 1 - saúde; CI 2 - orientação de valor/experiência anterior.

Categoria 5: A-ADAPTAÇÃO - diz respeito as unidades de análise envolvendo o movimento ao longo das fases neste contínuo, através da transição, observado no item compreendido a partir do embebimento total da personalidade a reorganização desta. 


\section{APRESENTANDO E DISCUTINDO OS DADOS}

Identificou-se para cada categoria descrita, as seguintes unidades de análise:

Na categoria 1 - TOE, cujos enunciados referem-se à transcrição de ocorrência de eventos e de não ocorrência de eventos, na transição emergiu as seguintes sub categorias:

TOE 1 - Nesta sub categoria a qual contempla as mudanças nas relações sociais a partir da ocorrência de eventos foram identificadas as seguintes unidades de análise: “... idade de menopausa... / ...ela queria se vingar de mim... / ...me culpava da doença dela... / ...brigava muito com a gente em casa... / ...eu trabalhava fora... / ...no começo foi até bom... / ...passei crises...".

TOE 2 - Diz respeito à possibilidade de crescimento ou deterioração, do desenvolvimento da pessoa, abrangendo as seguintes unidades de análise: “... entrei em crise novamente... / ...meu pai bebia muito... / ...ele chegava em casa de manhã... / ...voltava bêbado... / ...jogando comida fora... / ...ele aposentou... / ...ficava em casa... / ...logo ele morreu... / ....a morte dele...".

TONE 1 - compreende as unidades de análise acerca da transição de não ocorrência de eventos, isto é, engloba as seguintes unidades de análise: “... não deu em nada... I I...não deu em nada... I ...não bebeu demais....;

TONE 2 - refere-se à transição de não ocorrência com possibilidade de não deterioração, evidenciadas nas seguintes unidades de análise: “... presenciava muitas discussões... / ...entrei em crise de novo.../ ...ele ia no bar...ele bateu em mim com uma barra de ferro...".

Para SCHLOSSBERG (1982), embora uma transição pode ser motivada a partir de mudanças esperadas, ou não, sempre está relacionada a ganhos ou perdas, podendo ser considerados estes aspectos tanto positivos como negativos.

É um processo onde o indivíduo passa de um estado de total preocupação a estados de reestruturação e integração. Em sua visão, o indivíduo por si só é capaz, de se adaptar a estes processos no decorrer da vida.

$\mathrm{Na}$ categoria CAS, diz respeito as características da transição em si mesma, cujas unidades de análise encontram-se nas seguintes sub categorias: CAS 1 esta sub categoria corresponde as unidades de análise que abordam as mudanças de papel, descritas como: "...eu cuidava da casa.../ ...eu trabalhava em consultório dentário.../ ...eu trabalhava só meio período.../ ...ele trabalhava como guarda noturno...l ...ele fazia companhia para minha mãe.../ ...eu trabalhava o dia todo.../ ...escola..."; CAS 2 - as emoções/sentimentos (positivas e negativas), contidas nesta sub-categoria são referentes às seguintes unidades de análise: "...na verdade eu estava mesmo com medo.../ ....até que ele ficou só comigo.../ ...me deixava de lado.../ ...não tenho vontade de procurá-lo.../ ...ela queria se vingar de mim.../ 
...ficava muito violento.../ ...me deixou triste.../ ...ela percebeu que me deixava aborrecida.../ ...me atingia muito.../ ...não se vingar é a palavra certa.../ ...não me conformo.../ ...ele disse que estava com medo.../ ...eu vivia apavorada.../ ...não me conformei.../ ...chorava o tempo todo.../ ...eu estava entusiasmada com ele.../ ...não tenho certeza.../ ....brigava comigo.../ ...eu não dizia.../ ...eu negava.../ ....no fundo tenho vergonha da situação,.../ ...não tinha tempo para se encontrar comigo.../ ...não me conformava.../ ...acho que a paixão acabou.../ ...ele não se separava de vez da mulher.../ ...significava...ele não levava a sério.../ ...trocada pelo serviço.../ ...ela queria desforra...".

Observou-se entre as categorias descritas que o maior número de falas da entrevista, esteve relacionado com a categoria acima mencionada ou seja, as emoções/sentimentos (positivas e negativas). Tal fato aponta à luz do modelo utilizado de SCHLOSSBERG 1982, que uma transição é condicionada segundo o aparecimento ou não, de eventos resultantes de mudanças no autoconceito e na percepção do indivíduo em relação ao mundo e conseqüentemente, suas relações com as mudanças comportamentais deste. Logo, os dados revelam-se neste estudo, a partir de eventos relativos à mudança de papel, a sentimentos e/ou emoções e ao grau de ansiedade descrito na subcategoria correspondente. Com isto mostrou-se que estes sentimentos e/ou emoções intervêm no modo de lidar com as crises.

CAS 3 - O grau de ansiedade encontra-se nas seguintes unidades de análise: “... eu só via de vez em quando... / ...quebrando tudo em casa... / ...voltou... / ...eu ficava apavorada... / ...chorava o tempo todo". Evidencia-se então, que a ansiedade por ser às vezes positiva ajuda a pessoa a tomar decisões acertadas durante uma crise. Também pode tomar uma dimensão em que a pessoa descontrola-se e não consegue perceber as saídas por mais simples que as pareçam, talvez por precaução, /medo ou pânico.

$\mathrm{Na}$ categoria CAPA encontrou-se as seguintes sub categorias que aludem características pré e pós-transição:

CAPA/t1 - compreende os sistemas internos de apoio referentes a: relação de intimidade, unidade de família e rede de amigos. Encontram-se destacadas nas seguintes unidades de análise: “... não quis abrir processo contra ele... / ...arrumei um namorado... I ...ele era casado... I ...vivia rodeado de mulheres... I ...tinha várias namoradas... / ...minha mãe desconfiava... / ...jogando indiretas...";

CAPA/t2 - para os suportes institucionais, ambiente físico e fatores culturais, identificou-se as seguintes unidades de análise: “... internada no sanatório várias vezes.../ ...minha mãe internada.../ ...sanatório de doentes mentais...".

SCHLOSSBERG (1982) ainda ressalta a necessidade de equilíbrio necessário entre recursos e deficiências incluídos na percepção que o indivíduo tem a esse respeito, como resultante da experiência real em lidar com as crises.presentes e passadas.

Tal fato nos remete ao primeiro recurso onde as pessoas utilizam de si mesmas. Quando se esgotam seus recursos pessoais e seus mecanismos de 
enfrentamento de dificuldades é que estas mais freqüentemente usam os recursos externos, ou seja, suportes institucionais. Estes últimos, geralmente são requeridos quando a ansiedade atingiu tal intensidade que a pessoa não percebe outra saída, ou quando já se instalou um processo doentio.

$\mathrm{Na}$ situação presente a pessoa alegou ter superado a transição sem precisar desses recursos para si, mas apenas para sua mãe, que foi o elemento que adoeceu durante o processo. Observou-se que ela aponta a mãe como "a paciente identificada" que necessita de ajuda, contudo questionamos acerca do entendimento da transição como sendo mais abrangente a qual engloba a família.

$\mathrm{Na}$ categoria $\mathbf{C l}$ - relativa às características do indivíduo, é composta pelas seguintes sub categorias:

CI 1 - Aborda temas referentes à saúde - nesta subcategoria foram observadas as seguintes unidades de análise: “... minha mãe ficou doente... /...ele não conseguiu dormir... I...minha mãe piorou... I...fez vários exames... /...reclama de uma dor na barriga...".

CI 2 - Refere-se à orientação de valor e/ou experiência anterior relatada. Estão contidas nesta sub categoria as seguintes unidades de análise: “... considerada de psicológica... /...ela pedia para o médico interná-la... / ...vivia separado da mulher... I ...era bem mais velho...".

Na categoria - A - Adaptação encontra-se representada pelas seguintes unidades de análise: “... até hoje continua com dor... /...fez isso até hoje... /...agora aprendi a conviver com isso... /...melhorou muito... /...assim está sendo até hoje... o tempo passou... I...estou mais tranqüila...".

Salienta-se que, no tocante à transição em si mesma, esta pode igualmente afetar a adaptação a partir de aspectos como mudança de papel, mudanças afetivas, duração e grau de ansiedade, origem, ritmo, fonte e forma de aparecimento da transição, de acordo com SCHLOSSBERG (1982).

Observa-se ainda, que os graus e facilidades de adaptação, são específicos de cada indivíduo. Daí pode-se inferir, neste estudo de caso, uma tendência desta mulher adulta de inserir-se na adaptação, segundo o modelo proposto e evidenciada nos seguimentos de falas acima mencionadas.

\section{AMARRANDO OS OBJETIVOS}

A entrevista realizada segundo postura e um roteiro pré-estabelecido, ofereceu subsídios aos pesquisadores para a obtenção de relevantes dados.

Evidencia-se no depoimento da entrevistada, que enquanto adulta passa por transições. Nota-se no caso, que na pré, durante e pós-transição foi evidenciada 
na mulher: ansiedade e sentimentos antagônicos como raiva, alegria, tristeza, medo, entre outros. Observa-se que ela conseguiu passar pelas transições utilizando-se de recursos pessoais visualizadas nos itens arrolados, no modelo descrito anteriormente, como características do ambiente pré, pós-transição e na transição de si mesma.

Isto mostra que "ficar de braços cruzados" é uma atitude, às vezes tão cheia de sentimentos como a de ações. Sua ansiedade até certo grau, mesmo estando presente, representa uma força propulsora a qual the conduzia a uma passagem da transição, com mais segurança e coragem.

Vale aqui refletir sobre o olhar da enfermeira sobre o cliente/paciente ao ficar de "braços cruzados". Presa a preconceitos pode inferir sua impotência diante da crise. O que não é raro encontrar tal atitude das próprias enfermeiras. Muito embora aparentemente inativo, a pessoa tem seu mundo interior e passa nele uma série de emoções, lembranças, comparações que ajudam a sair-se vencedora ou vencida, a fluir ou a permanecer irracional diante da fase de transição.

Assim sendo, a possibilidade de assumir uma atitude de entrevistadores ancoradas em SCHLOSSBERG (1982), significa estar aberta para receber depoimentos sem expectativas, buscando material de várias fontes e procurando libertar-se das possíveis "percepções congeladas". Desta maneira, foi o que se procurou realizar no presente estudo.

Além disso, a entrevista assim conduzida levou os entrevistadores a constatar a facilidade que se tem nesta posição. Enquanto isso eles dão margem a entrevista para se colocar livremente e oferecer espaço para que esta pense em facetas ocultas de si mesmo, dando assim a própria entrevista em caráter terapêutico.

Em suma, refletir sobre a importância tanto dos dados obtidos sobre a pessoa em transição, na aplicabilidade do modelo visando estar vivenciando uma postura não normativa na coleta de dados, resgata as seguintes considerações: a procura de outros focos na entrevista, os quais foram observados nesse estudo ao verificar-se que a mãe é que adoeceu, o que caracteriza também uma transição por encontrar-se inserida como um dos elementos que compõem o ambiente pré e pós-transição. E por se tratar de mãe, possivelmente isto tem grande peso como elemento desencadeante de um redimensionamento de vida.

Vale ressaltar, que este estudo leva a se pensar que os profissionais de enfermagem devem estar atentos a tais fatos, interagindo com adultos $\mathrm{e}$ conseqüentemente, com os que fazem parte do complexo ambiental, na identificação dessas passagens.

Finalmente, assumindo um modelo não normativo a enfermeira terá recebido contribuição atualizada no entendimento da pessoa como ser único, vivendo seu momento conforme sua possibilidade. Logo, isto favorece que se minimize a ação dos preconceitos, evitando enquadramentos capazes de conduzir o enfermeiro a impor seus próprios pensamentos, centrado nos seus valores, hábitos e costumes. 


\section{TRANSITIONS DESCRIBED BY AN ADULT WOMAN - SUBSIDIES FROM THE HUMAN ADAPTATION MODEL OF SCHLOSSBERG}

The case study of a forty two years old woman expressed the transition and crisis experienced by an adult woman. The speech content is presented in this article according to the human adaptation model of SCHLOSSBERG and attempting to acquire informations about crisis and transitions. The authors assumed a position of non-normative interviewers applying a psychological model in nursing and used the content analysis technic. They verified that the adult woman crises were solved using her own personal resources.

UNITERMS: adult woman, non-normative, transition

\section{TRANSICIONES Y CRISIS RELATADAS POR UNA MUJER ADULTA - AYUDAS AL MODELO DE ADAPTACIÓN HUMANA DE SCHLOSSBERG}

A través de un estudio de caso, de una mujer de 42 años, fueron expresadas sus transiciones y crisis vividas. El contenido del habla es presentado en este trabajo, utilizando el modelo de adaptación humana propuesto por SCHLOSSBERG, con el objetivo de obtener informaciones sobre crisis y transiciones, se asumió la postura de entrevistador no normativo y se aplicó un modelo originario de la psicología en la Enfermería. Se ha utilizado el análisis de contenidos para clasificar el material de las entrevistas. En los resultados del estudio se constata que la mujer adulta ha conseguido superar las crisis, en dirección de su adaptación, utilizando recursos personales.

UNITERMOS: mujer adulta, no-normativo, transición

\section{REFERÊNCIAS BIBLIOGRÁFICAS}

01. BARDIN, L. Análise de conteúdo. Lisboa: Edições 70, 1991.

02. MINAYO, M. C. de S. (org.). Pesquisa social: teoria, método e criatividade. Petrópolis: Vozes, 1994.

03. SCHLOSSBERG, N. Y. A model for analyzing human adaptation to transition.

Counse I.Psychologist, v. 9, n. 2, p. 2, 1982. 